FINAL REPORT

U. S. Department of Energy

\title{
Photocatalytic and Chemical Oxidation of Organic Compounds in Supercritical Carbon Dioxide
}

\author{
Daniel M. Blake, Ph.D. \\ National Renewable Energy Laboratory \\ Golden, Colorado
}

Project Number: 54847

Project Officers: Mark Gilbertson and Roland Hirsch

Project Duration: January 1, 1997 to September 30, 2000 


\section{Table of Contents}

Table of Contents: $\quad 2$

Executive Summary 3

Research Objectives $\quad 3$

Methods and Results $\quad 4$

$\begin{array}{ll}\text { Relevance, Impact, and Technology Transfer } & 11\end{array}$

$\begin{array}{ll}\text { Project Productivity } & 12\end{array}$

$\begin{array}{lr}\text { Personnel Supported } & 12\end{array}$

$\begin{array}{ll}\text { Publications } & 13\end{array}$

$\begin{array}{ll}\text { Interactions } & 13\end{array}$

$\begin{array}{ll}\text { Transitions } & 14\end{array}$

$\begin{array}{ll}\text { Patents } & 14\end{array}$

$\begin{array}{ll}\text { Future Work } & 14\end{array}$

$\begin{array}{ll}\text { Literature Cited } & 14\end{array}$ 


\section{Executive Summary:}

Carbon dioxide is viewed as an environmental boon - in the context of replacing organic solvents that can result in air and water pollution. At the same time $\mathrm{CO}_{2}$ is implicated as a major threat to the global environment - due to its greenhouse effect when released by the consumption of fossil fuels for energy production. Supercritical $\mathrm{CO}_{2}$ systems are under development for applications in treating mixed and hazardous wastes. Another important application of supercritical carbon dioxide is in the area of cleaning electronic components, micro -devices, and other parts where the advantages of low viscosity and solvent properties have a high value. This work demonstrates that photocatalytic oxidation can be used to remove trace organic contaminants from carbon dio xide in the supercritical, liquid, and gas phases. This has applicability in processes where it is desirable to recycle the carbon dioxide in contaminant sensitive applications.

\section{Research Objectives:}

The goal of the proposed research is to develop new chemistry for the removal of organic contaminants from supercritical carbon dioxide. This has application in processes used for continuous cleaning and extraction of parts and waste materials. Cleaning and extraction using supercritical carbon dioxide $\left(\mathrm{scCO}_{2}\right)$ can be applied to the solution of a wide range of environmental and pollution prevention problems in the DOE complex. The objectives at the outset of the project were to:

1) determine if photocatalytic or other clean oxidation chemistry can be applied to the removal of organic or inorganic contaminants that are introduced into supercritical carbon dioxide during its use as an extraction and cleaning medium. The target will be contaminants left in solution after the bulk of solutes have been separated from the fluid phase by changing pressure and/or temperature (but not evaporating the $\mathrm{CO}_{2}$ ). This is applicable to development of efficient separations and will strengthen pollution prevention strategies that eliminate hazardous solvents and cleaning agents.

2) explore the use of supercritical carbon dioxide as a solvent for the photocatalytic oxidation of organic compounds and to compare it to other types of oxidation chemistry. This will add to the fundamental understanding of photocatalytic oxidation chemistry of particulate semiconductors and provide new knowledge about conditions that have relevance to the chemical fixation of carbon dioxide.

\section{Background:}

Applications of supercritical carbon dioxide are being explored that will exploit the potential for replacement of organic solvents and ozone depleting compounds in cleaning and degreasing applications ${ }^{1,2}$ and in removal of contaminants from soil. ${ }^{3}$ In addition to the environmental, safety, and health benefits there are advantages for chemical processes in its resistance to oxidation, miscibility with reactive gases $\left(\mathrm{O}_{2}, \mathrm{H}_{2}\right.$, and low molecular weight organic gases), and ease of recovering reaction products.

Heterogeneous catalytic oxidation of organic compounds ${ }^{5,6,7,8}$ have been studied. Conditions normally require temperatures up to about $150 \mathrm{C}$ and presures in the range of 200 bar when noble metal catalysts are used. The goal has been to develop selective oxidation chemistry using clean oxidizing agents such as oxygen.

In contrast to the work on synthetic applications of heterogeneous thermal catalytic oxidation, photocatalytic oxidation using titanium dioxide as the catalyst has been studied primarily for applications in which total oxidation or organic compounds to carbon dioxide is the goal. ${ }^{9}$ However synthetic applications of photocatalytic chemistry are an ongoing subject of study using conventional solvents. ${ }^{10}$ Synthetic work includes that for organic compounds in organic solvents and attempts to achieve reduction of carbon dioxide to useful compounds using water as the solvent.

The lack of selectivity, which is a hindrance to synthetic applications, is a benefit when the goal is to eliminate organic or biological contamination from water, air, other fluids, or from surfaces. The surface cleaning effect has bearing on potential applications of photocatalytic oxidation in supercritical oxidation in that the ability to oxidatively clean catalyst surfaces is important in prevention of fouling and deactivation. 


\section{Methods and Results:}

Experimental Methods

Figures 1,2, and 3 show views of the photoreactor unit and experimental apparatus.

Figure 1. Photoreactor filled with a top layer of $\mathrm{TiO}_{2}$ coated Pyrex beads and lower layer of uncoated beads.

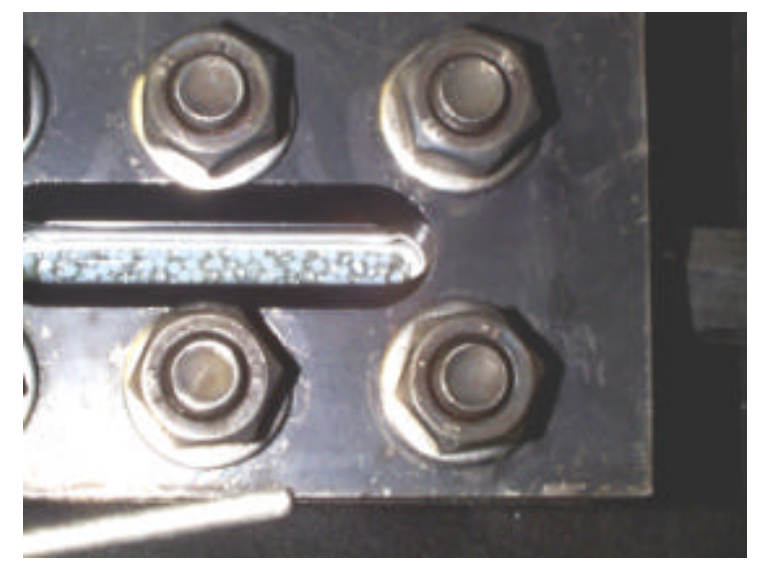

The experiments were done in a batch reactor with continuous. This type of reactor requires that the per pass conversion over a catalyst be small such that the composition is uniform throughout the loop at any time. Online sampling was done by removing 20 microliter samples through an automated valve coupled to a gas chromatograph (GC).

The high pressure flow cell with an empty volume of $14.9 \mathrm{ml}(12.7 \mathrm{~mm} \mathrm{X} 12.7 \mathrm{~mm} \mathrm{X} 92.1 \mathrm{~mm})$ was used as the reactor. Glass beads, $3 \mathrm{~mm}$ in diameter, were coated with $\mathrm{TiO}_{2}$. The glass beads were placed in the flow cell in various configurations depending on the experiment. Most of the experiments were done with either a layer or a half layer of catalyst-coated beads on the layer closest to the glass window and UV lamp. The remainder of the reactor volume was filled with uncoated glass beads of similar size. The reactor volume was reduced to an estimated $6 \mathrm{ml}$ with the glass beads in place. The reactor was oriented with the flow cell horizontal. A UV-lamp was positioned above the reactor with light passing through the glass and illuminating the photocatalyst. A metal screen was used at the entrance and exit of the flow cell to prevent catalyst beads from blocking the passages.

Circulation was provided with a positive displacement, magnetically coupled gear pump. The pumping rate was set with a manually adjusted control knob. The maximum flow rate was limited by the magneticdriven pump head decoupling from the motor drive. If the pump head decoupled from the drive, the pump flow terminates immediately. Since the experiments were unattended, if the pump stopped working during an experiment, the results were invalidated. Therefore, a safety margin for the maximum flow rate was maintained to minimize the chance of losing the pump during a run. The volumetric flow rate for the pump was between $0 \mathrm{ml} / \mathrm{min}$ and $80 \mathrm{ml} / \mathrm{min}$ depending on the user selected setting for the pump.

The flow rate and fluid density in the system were measured using a coriolis mass flow meter manufactured by MicroMotion (Sensor: Elite high pressure, CMF010P; Transmitter: Elite, RFT9739 dual output (flow and density); Nominal flow-rate: 0 to $82 \mathrm{~kg} / \mathrm{hr}$, Flow Accuracy: +/- $0.75 \%$ of flow-rate, Density Accuracy: $+/-0.002 \mathrm{~g} / \mathrm{cc}$ ). The system pressure was measured with a pressure transmitter with a range of 0 to 3000 psig \pm 3 psi. The transmitter signal was recorded using a National Instruments data A/D input board together with the Labview data acquisition software.

A multiport valve was used to inject small quantities of hydrocarbons into the $\mathrm{CO}_{2}$ loop. Using a 10 microliter graduated syringe, between 1 and 4 microliters of liquid hydrocarbons were injected into an unpressurized loop on the valve. The valve handle was repositioned to divert the flow of $\mathrm{CO}_{2}$ through the 
injection loop for 30 to 60 seconds before returning the flow to the normal flow path. The hydrocarbon dispersed throughout the loop as it recirculated through the pump, flow meter, and reactor vessel. The concentration of hydrocarbon was monitored by GC until the level appeared to be constant.

A Sylvania 100 watt Par 38 Mercury UV lamp (primary output at $365 \mathrm{~nm}$, flux about $5.7 \mathrm{~W} / \mathrm{m}^{2}$ at the catalyst) was set above the reactor. A timer was used to activate the power to the light. This permitted the hydrocarbon to be thoroughly mixed without a technician being present to turn on the light after several hours and facilitated starting an experiment in the late afternoon and running over night.

The flow loop was constructed mainly of 1/8" high-pressure tubing with an inside dia meter of $1 / 16$ " inches. The total loop volume, including the reactor with catalyst and glass beads was $56.5 \mathrm{ml}$. The volume was determined by expanding helium gas at 1488 psia in the system into a high-pressure bomb of known volume. The pressure change was related to the volume change using the ideal gas law.

The entire system except for 24 inches of tubing that ran to and from the g.c. was enclosed in a polycarbonate box. A small heater and circulation fans were used to keep the temperature inside the box uniform at a user-specified temperature of $40^{\circ} \mathrm{C}$. During operation, the heat from the UV lamp and heat from pumping controlled the temperature more than the box heater.

The GC used for concentration measurements was a HP5890 Series II with an HP-35 (30 m X $0.35 \mathrm{~mm}$ X $1.0 \mu \mathrm{m}$ film thickness) column. The oven temperature was $40^{\circ} \mathrm{C}$ for all experiments. Calibrations were done using cyclohexane in methanol at several concentrations between $10 \mathrm{ppm}$ and $100 \mathrm{ppm}$.

The procedure used for an experiment was as follows. Oxygen was introduced as a 20/80 $\left(\mathrm{O}_{2} / \mathrm{CO}_{2}\right)$ mixture and was usually maintained in large excess. The system was pressurized from a liquid $\mathrm{CO}_{2}$ cylinder which was increased to approximately 1300 psig with a hand pressure generator. The pump was turned on to circulate the $\mathrm{CO}_{2}$ through the system. Using a 10 -microliter syringe, between 1 and 4 microliters of hydrocarbon were introduced through a septum into an injection loop. The injection loop valve was turned to divert the $\mathrm{CO}_{2}$ through the injection loop and to sweep the hydrocarbon into the main flow loop. The injection loop was swept with $\mathrm{CO}_{2}$ for approximately 30 seconds. The sweep time was not a critical factor since the initial concentration was measured after the hydrocarbon had been dispersed in the system.

The flow loop was allowed to circulate for a period of several minutes to hours while the concentration was measured periodically (10 to 20 minute intervals) using the GC. The experiment was initiated when the lamp was turned on to expose the catalyst to UV light. The heat from the lamp increased the temperature of the flow loop for approximately 30 minutes which resulted in a concomitant increase in temperature and pressure.

The process was left running for several hours while the GC measured the concentration and the data acquisition software recorded the temperature, pressure, density and mass flow rate. After a period of time (up to 1000 minutes) depending on the initial concentration and the quantity of catalyst present in the reactor, the UV light was turned off and the experiment was terminated. The flow loop was vented to the atmosphere, and the system was prepared for the next experiment.

The catalyst was periodically regenerated using zero air at atmospheric pressure. A small quantity of air flowed through the reactor with the UV light on as in the previously described experiments. This regeneration was usually performed over a weekend and lasted 24 to 48 hours. 


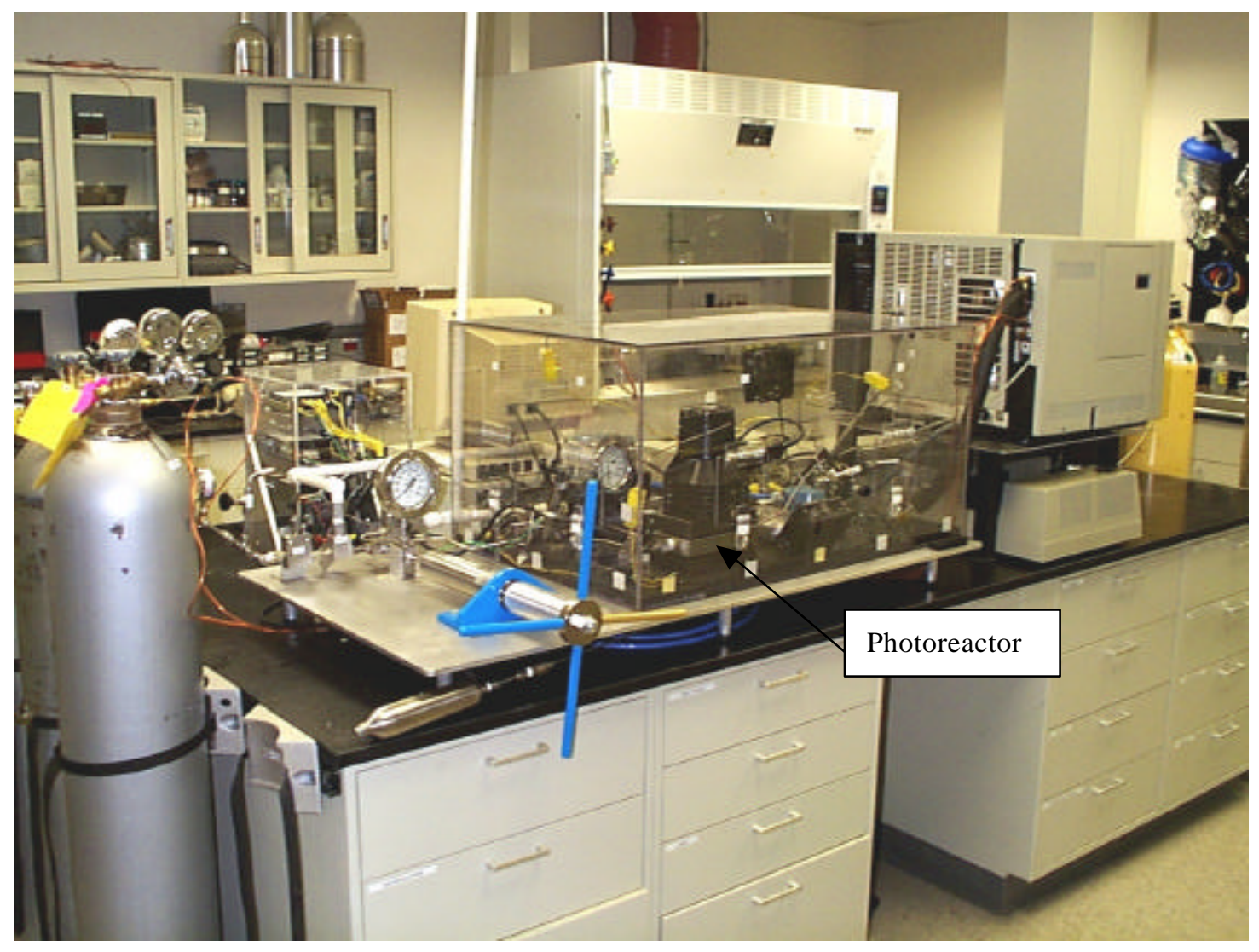

Figure 2. Front view of the experimental system.

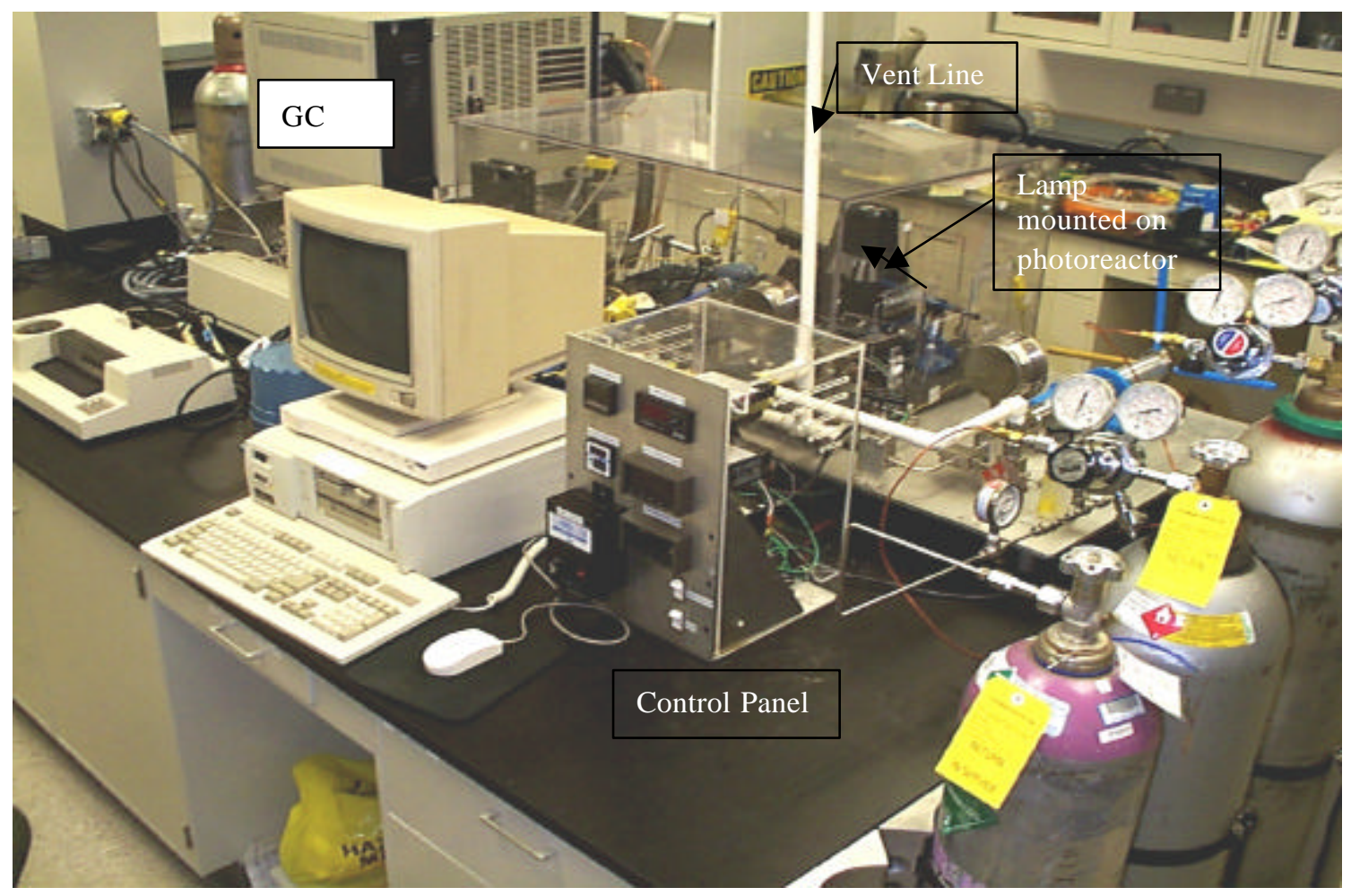

Figure 3. Back view of the experimental system showing the control panel. 


\section{Principal Results}

In the first phase of the project we compared model organic compounds and the effects of the phase of the fluid medium. Representative reaction conditions are: initial concentration of the organic compound is approximately $2000 \mathrm{ppm}$; initial concentration of $\mathrm{O}_{2}>50$ times stoichiometric amount; the photocatalyst is Degussa P25 $\mathrm{TiO}_{2}$ on $5 \mathrm{~mm}$ glass beads; gas phase experiments were performed at $\sim 10$ psig and $25 \mathrm{C}$; supercritical phase experiments were performed at $\sim 1200 \mathrm{psig}$; T $\sim 37 \mathrm{C}$; and the reaction vessel was illuminated with a 100 watt spot lamp with output centered at $360 \mathrm{~nm}$.

Results are shown in Figures 4 through 7. The results for hexane, toluene, cyclohexane, acetone and benzene oxidation in synthetic air are shown in Figure 4. The rate of oxidation of benzene is typically lower than other hydrocarbons. There is evidence that intermediate oxidation products (e.g. phenol, catechols, and quinones) are strongly adsorbed on titanium dioxide and the rate is determined by the time required to oxidize these intermediate products and create free sites for benzene. ${ }^{11}$ Comparison of the oxidation of the same compounds in a carbon dioxide/oxygen mixture yielded similar results as is shown in Figure 5. Carbon dioxide had little effect on the rates in the gas phase reaction.

Figure 4. Oxidation of Organics in $\mathrm{N}_{2} / \mathrm{O}_{2}(80: 20)$

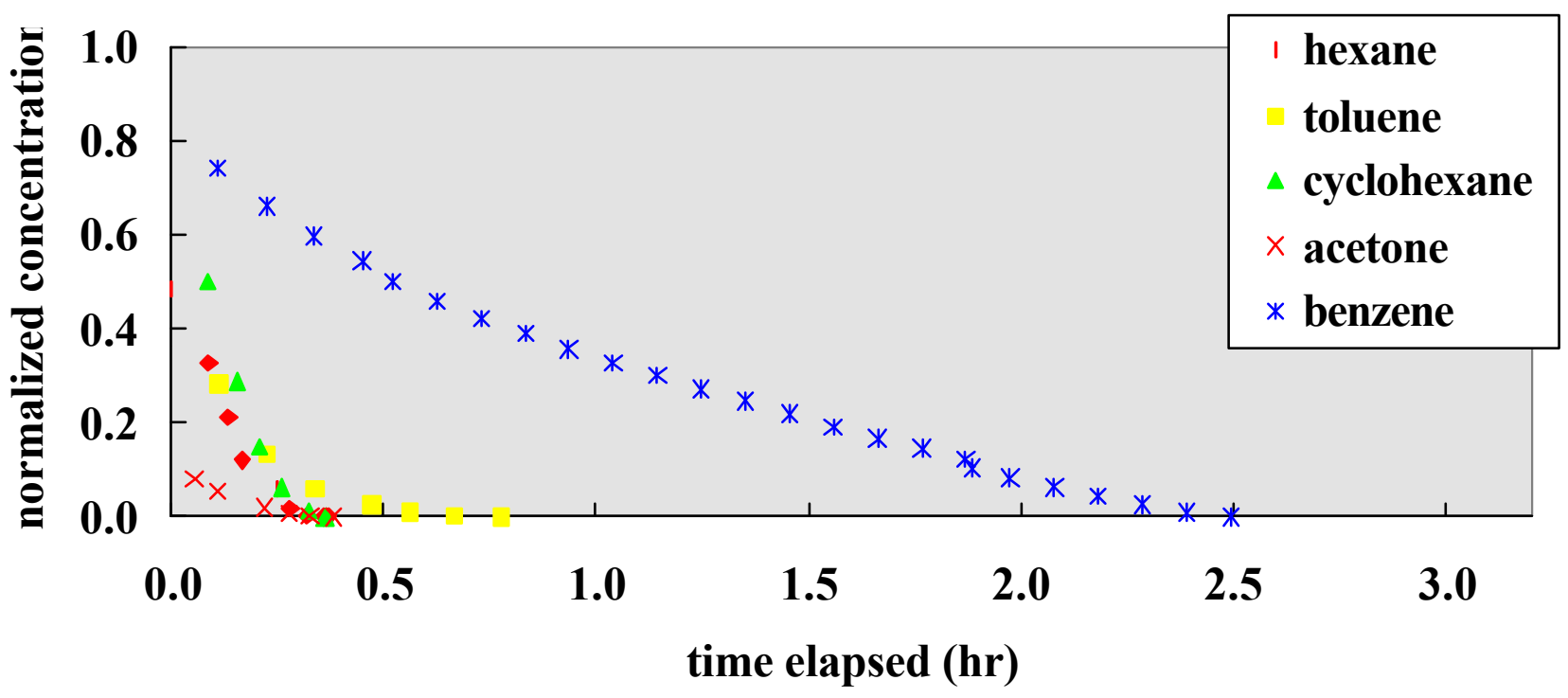


Figure 5. Oxidation of Organics in Gas Phase $\mathrm{CO}_{2} / \mathrm{O}_{2}(80: 20)$.

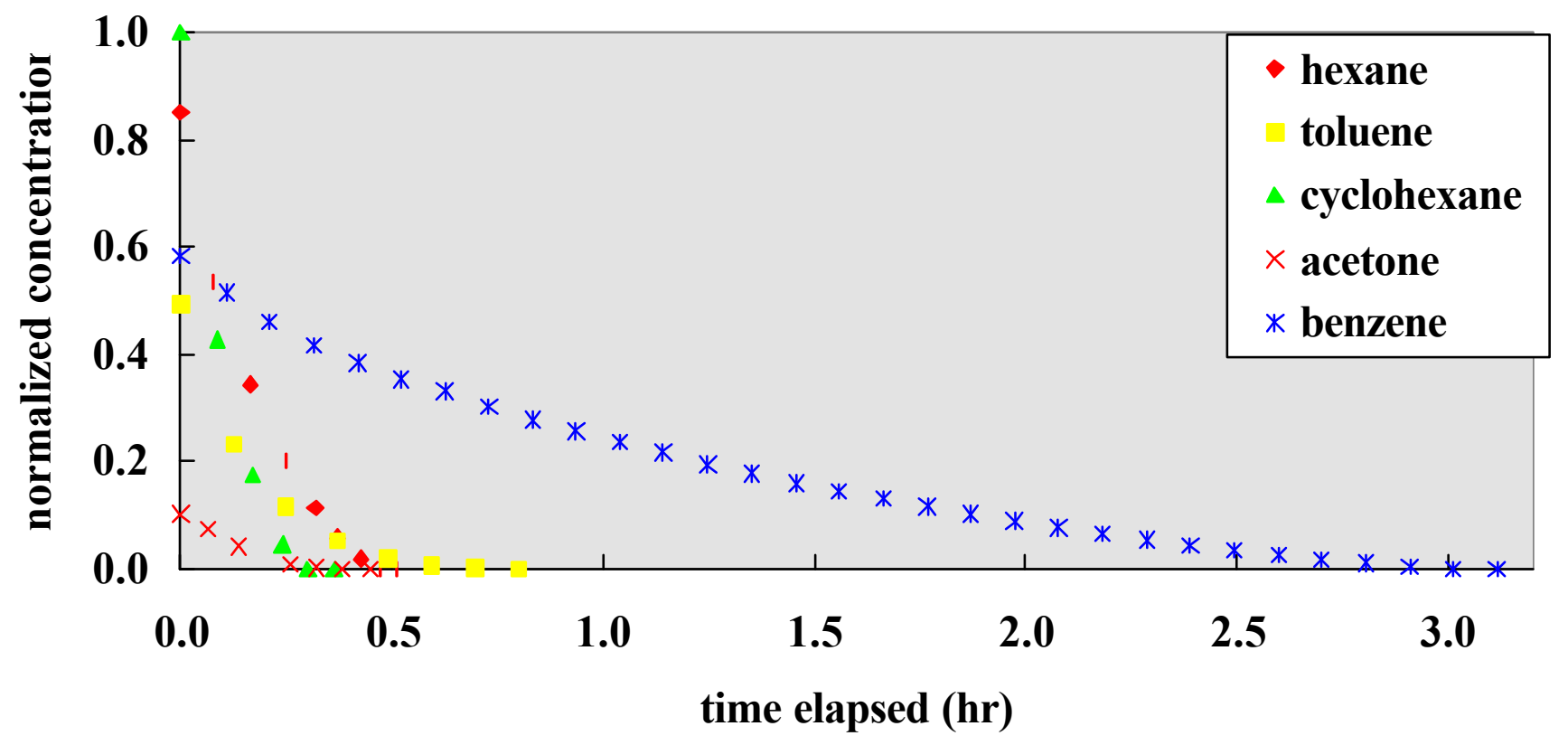

Figure 6. Hexane Oxidation in Gas Phase $\mathrm{N}_{2} / \mathrm{O}_{2}$ or $\mathrm{CO}_{2} / \mathrm{O}_{2}$ and in Supercritical $\mathrm{CO}_{2} / \mathrm{O}_{2}$

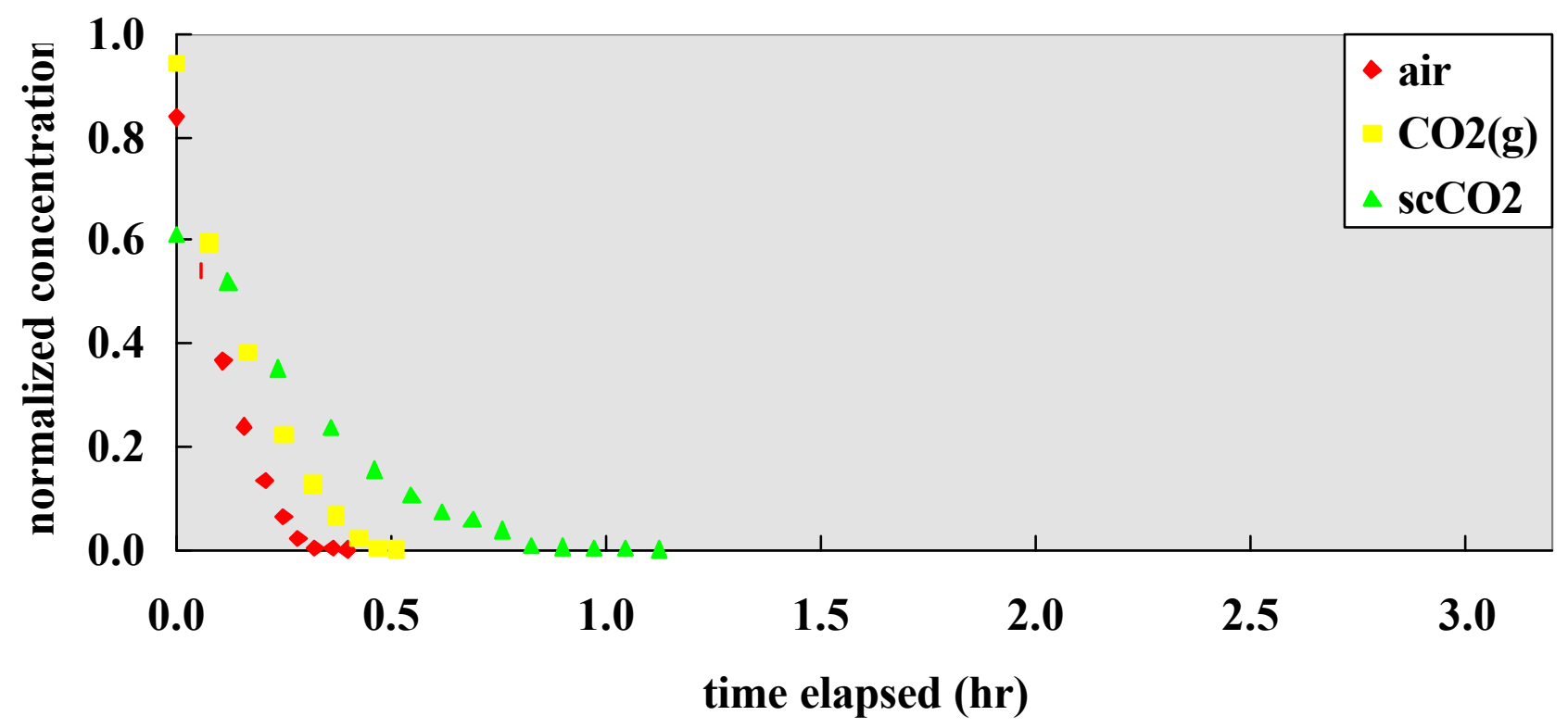


Figure 7. Benzene Oxidation in $\mathrm{N}_{2} / \mathrm{O}_{2}$, Gas Phase $\mathrm{CO}_{2} / \mathrm{O}_{2}$ and Supercritical $\mathrm{CO}_{2} / \mathrm{O}_{2}$

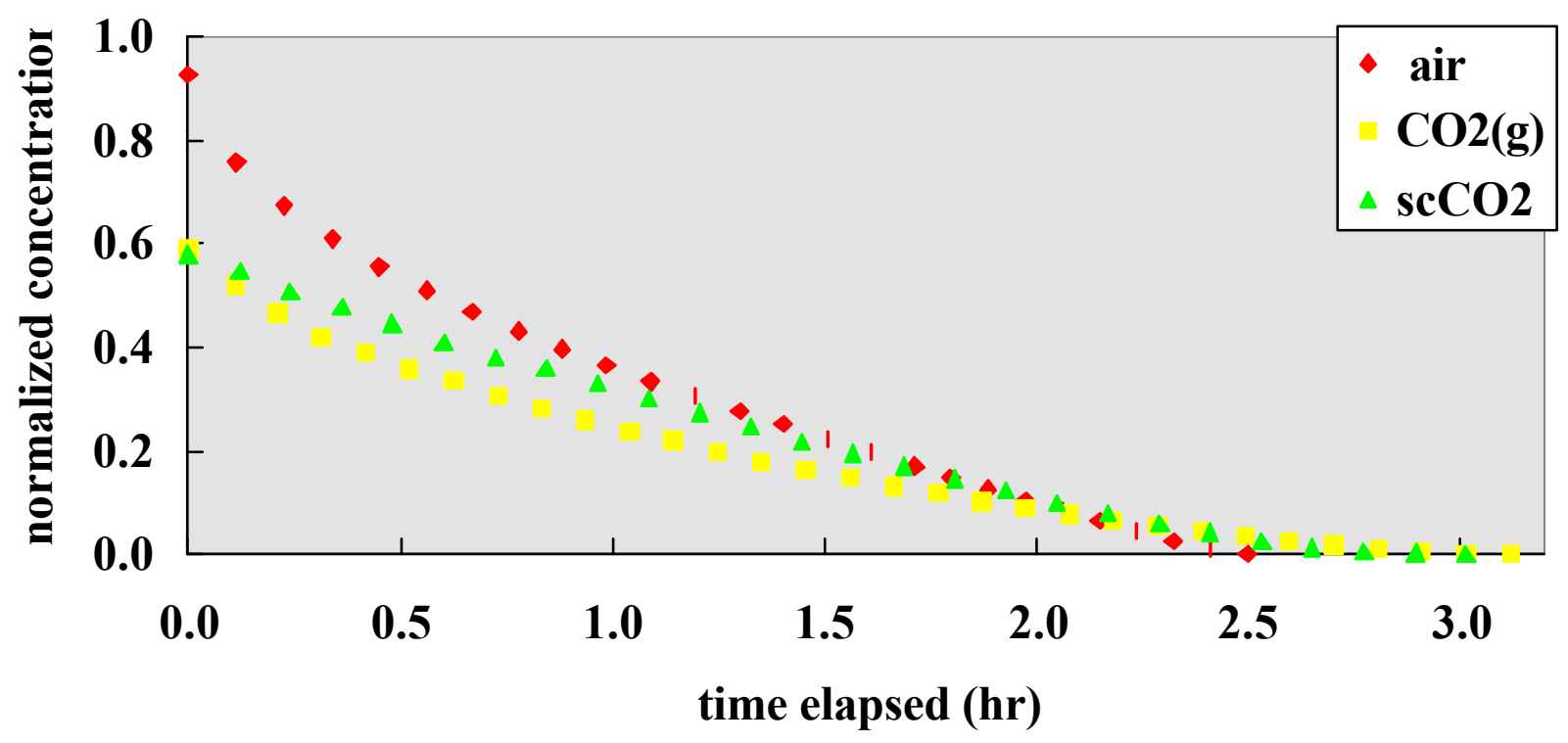

Figure 6 shows that the rate of oxidation of hexane is moderately lower in supercritical $\mathrm{CO}_{2}$ compared to the gas phase. For benzene, Figure 7, there is little difference between the gas and supercritical phases. As mentioned above, the photocatalytic oxidation of benzene and other aromatic compounds is limited by the rate of oxidation of adsorbed, intermediate oxidation products to free surface sites. Supercritical $\mathrm{CO}_{2}$ is apparently not sufficiently polar to dissolve the intermediate oxidation products and keep the surface open for benzene oxidation.

In the second phase of work effort was focussed on oxidation of cyclohexane as a model to see how system parameters affected the removal. These results are shown in Figures 8-11. The photoreaction vessel is irradiated from the top. It was found that the top layer of catalyst coated beads was responsible for most of the reaction and fractional top layers were less effective than a full top layer, Figure 8.

Figure 8. Concentration of cyclohexane as a function of time for different catalyst quantities.

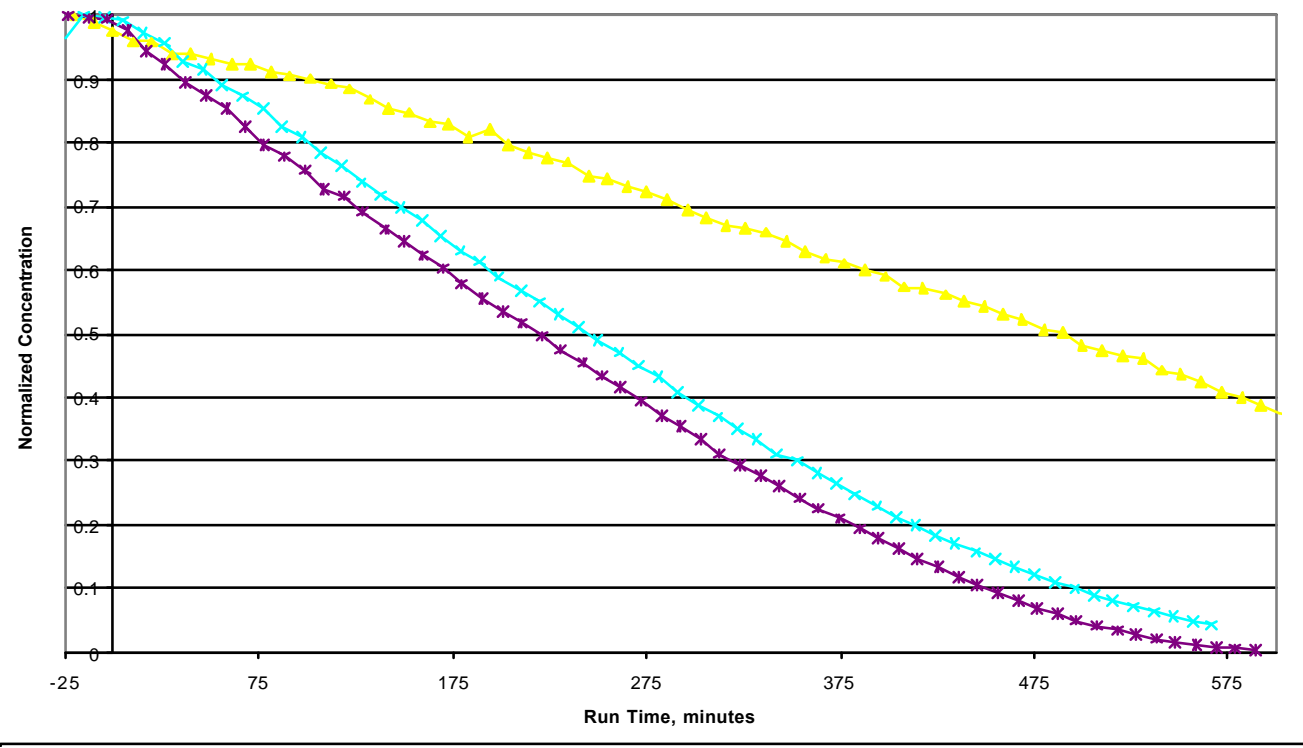


Figure 9. Concentration of cyclohexane as a function of time for high and low oxygen concentrations.

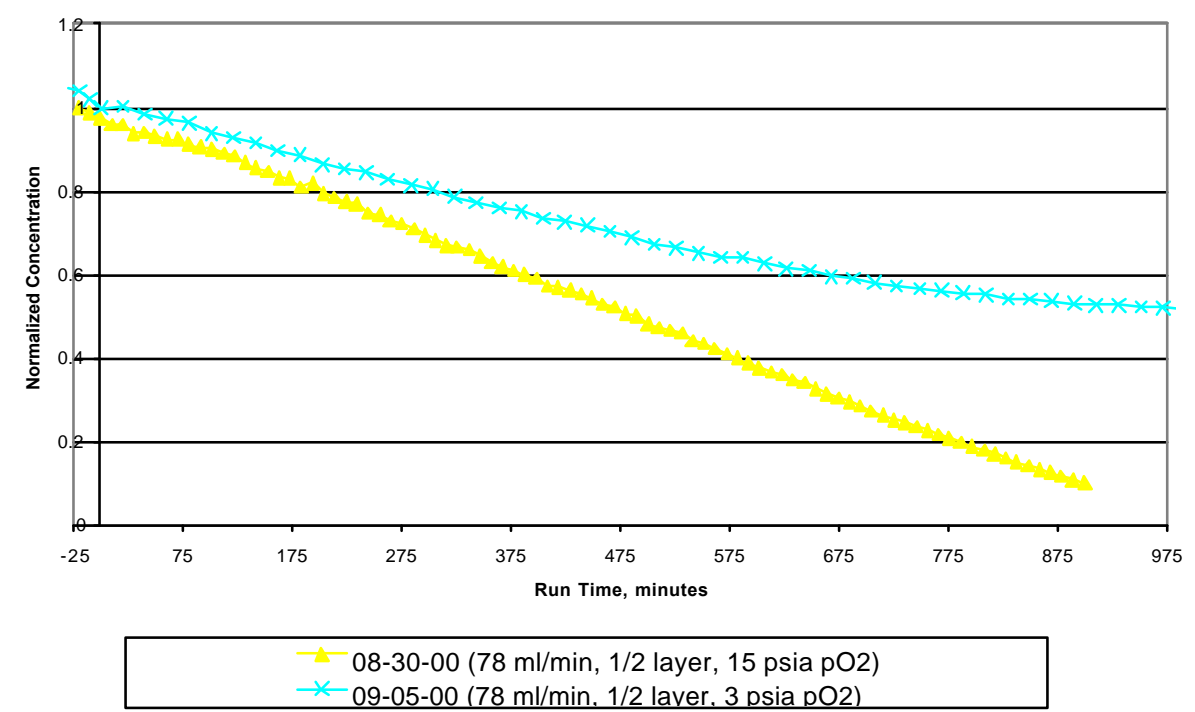

Figure 10. Concentration of cyclohexane as a function of time for high and low flow rates.

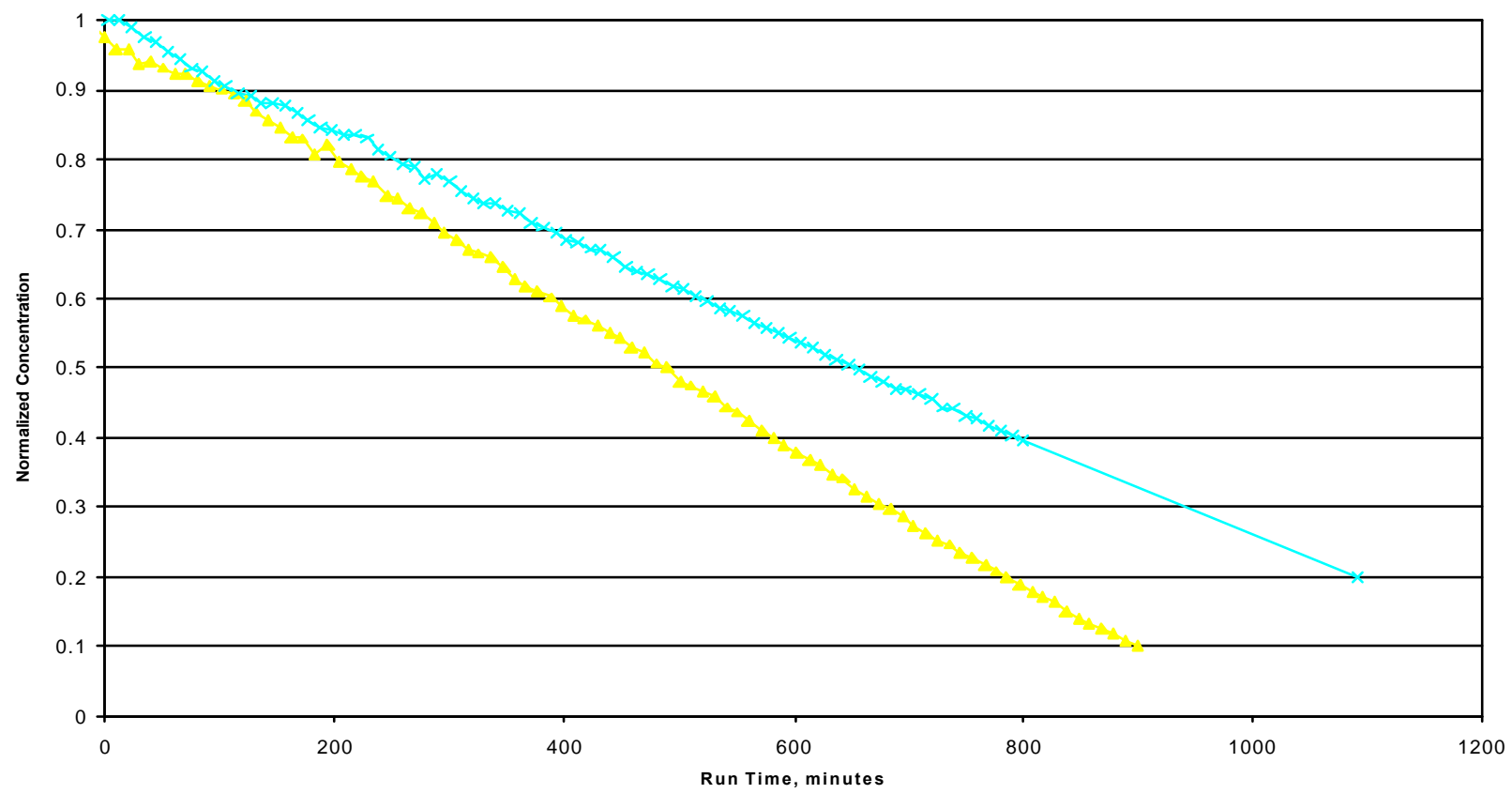

08-30-00 (78 ml/min, 1/2 layer, $15 \mathrm{psia} \mathrm{pO2)}-x-08-31-00(28 \mathrm{ml} / \mathrm{min}, 1 / 2$ layer, $15 \mathrm{psia}$ pO2 $)$

In Figure 9 it is shown that an initial filling of 15 psia oxygen is adequate for the complete conversion of cyclohexane so all runs were made with that concentration. The flow rate could be controlled within a narrow range. As is seen in Figure 10 the high flow rate increased conversion so was used in most 
experiments. Since higher flows could not be achieved in the system because of the limitation of the recirculating pump, we are not sure that the conversions are not mass transfer limited.

Figure 11. Concentration of cyclohexane as a function of time fresh Catalyst w/o light, fresh catalyst with light, used catalyst, and regenerated catalyst.

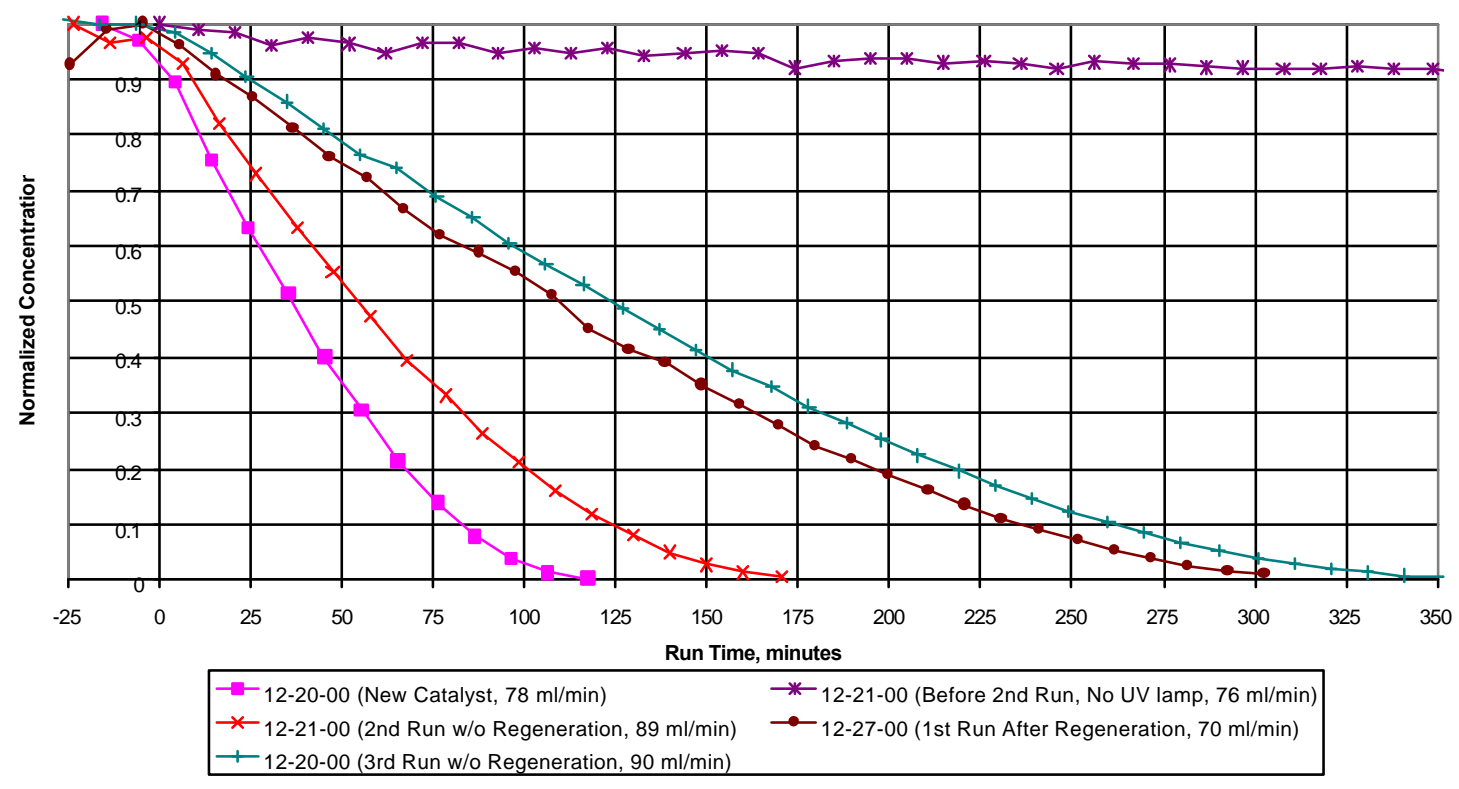

Figure 11 demonstrates the requirement for light for the oxidation of cyclohexane and that fresh catalyst is more active than used catalyst. The initial activity of the catalyst was not recovered by irradiation while flowing clean air through the reactor. This is unusual when compared to regeneration of catalysts used during the treatment of air or water. This could be due to the fact that all experiments to date have been run under dry conditions. In air phase photocatalytic oxidation it is often observed that added water vapor improves catalytic activity and aids regeneration. ${ }^{12}$

In conjunction with projects funded from other sources, the principal investigator (and co-workers funded by the non-EMSP sources) studied removal of organic and microbial contamination from titanium dioxide photocatalyst surfaces. This work established that whole bacterial cells and high molecular weight compounds such as polysaccharides, proteins, and lipids are oxidized to carbon dioxide on titanium dioxide under illumination with oxygen present. ${ }^{12}$ Earlier work at NREL and elsewhere has established that adsorbed organic compounds and oil films can be removed from titanium dioxide surfaces under irradiation with near UV light in the presence of oxygen in liquid or gas fluid phases. ${ }^{9}$

\section{Relevance, Impact, and Technology Transfer:}

a. DOE environmental requirements Supercritical carbon dioxide or other fluids are being studied for application in environmental cleanup, decontamination of waste materials, and for cleaning of parts. The technology from this project would have application in high value applications where recycling of clean supercritical fluid may be required. The work done here also demonstrates that organic contaminants can also be removed from gas phase carbon dioxide. This provides a second alternative for purification of carbon dioxide for recycle in a cleaning application. Purification of carbon dioxide gas could be done at low pressures (one or a few atmospheres) which would make the engineering of photochemical reactors much easier. A third alternative would be to use photocatalytic cleaning of gas phase carbon dioxide if it 
was vented to the atmosphere and removal of organic contamination was required to meet air emission standards.

b. Benefits of new scientific knowledge It is likely that the subject technology for the supercritical phase would only have application in high value operations where recycle of the carbon dioxide is required. In those cases where the carbon dioxide is vented after use the photocatalytic purification can be applied to remove low level organic contaminants from the gas stream to prevent hazardous air emissions.

c. Bridging the gap between fundamental science and applications The time frame for development of this kind of chemical operation depends on the development of supercritical fluid or liquid phase carbon dioxide technology for DOE environmental or process requirements.

d. Impact on individuals and laboratories The work done provided new experience to the postdocs, students, and DOE lab staff that worked on the project. In addition the capability developed for study of photochemisty in supercritical carbon dioxide is applicable to process development of the type proposed for the project and in the bigger picture has relevance to work on carbon dioxide mitigation and photo and thermal conversion to carbon dioxide to chemicals and fuels.

e. Larger scale trials This project has proved technical feasibility but there are a number of steps required before larger scale work is warranted. The work in this project proved the feasibility of removal of org anic chemical contamination from carbon dioxide in the gas, liquid, or supercritical phases. This can be a unit operation in an overall process that uses liquid or supercritical carbon dioxide for cleaning or extraction. Thus scale up will be appropriate when such a process is identified.

f. Scientific capabilities The postdocs and students gained experience in the important area of technology for application of supercritical fluids in chemical processing; photochemistry at high pressures; on line methods of analytical chemistry; design and construction of high pressure equipment; and automation of experimental operations, monitoring, and data collection.

g. Understanding of the area Information on photochemistry in supercritical fluids has been extended to include heterogeneous photocatalysis. All previous work had been in homogeneous systems.

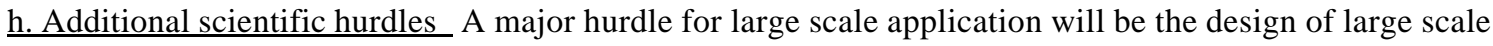
systems for photochemistry at elevated pressures which will hinge on methods for getting light into the reactors.

\section{i. Interest from other governmental agencies}

\section{Project Productivity:}

All goals except study of homogeneous oxidants such as hydrogen peroxide were accomplished. We did not pursue work on clean, homogeneous oxidizing agents due to lack of time. The implementation of the online analytical chemistry for the system took more time than we anticipated. It also was more difficult to achieve and measure controlled flow rates in the recirculating system than we planned for. We were able to leverage work funded for other projects to obtain key information on the self-cleaning effects of titanium dioxide surfaces under illumination with near UV light.

\section{Personnel Supported:}

Deborah Lee Bryant, Ph.D. - Postdoctoral fellow

Veronica Reinsch, Ph.D. - Postdoctoral fellow

Dr. John Scahill - Senior Chemical Engineer

Mr. Calvin Feik - Staff Engineer

Mr. Steven Phillips - Staff Engineer

Mr. Jason Vadaurri - Summer Research Student from Colorado State University 


\section{Publications:}

Blake, Daniel M., Pin-Ching Maness, Zheng Huang, Edward J. Wolfrum, Jie Huang, and William A. Jacoby. "Application of the Photocatalytic Chemistry of Titanium Dioxide to Disinfection and The Killing of Cancer Cells." Sep. Purif. Methods, 28, no. 1 (1999): 1-50.

Blake, Daniel M. "Bibliography of Work on the Photocatalytic Removal of Hazardous Compounds From Water and Air Update Number 3 to January, 1999."162 pp.Golden, CO: National Renewable Energy Laboratory, 1999.

Bryant, D. Lee, Daniel M. Blake, Steve Phillips, Calvin Feik, John Scahill, Jason Vadaurri, and Veronica Reinsch. "Photocatalytic Oxidation in Supercritical Carbon Dioxide," Manuscript in Preparation, (2001).

Wolfrum, Edward, Jie Huang, Daniel M. Blake, Zheng Huang, Pin-Ching Maness, and William A. Jacoby. "Total Oxidation of Bacteria, Bacterial and Fungal Spores, and Biofilm Model Compounds." Manuscript In Preparation (2001).

\section{Interactions:}

The PI and coworkers met with Professor Ted Randolph at the University of Colorado prior to the start of the project to gather information on methods for studying reactions in supercritical carbon dioxide.

The PI and a postdoc (DLB) attended the sessions in the symposium on supercritical fluids at the American Chemical Society meeting in Dallas, TX, in April 1998.

The PI presented posters at the EMSP workshops in Chicago and Atlanta.

Presentations on the photocatalytic work were made at the following:

In October, 1998, I traveled to Japan at the expense of the Agency of Industrial Science and Technology, and gave talks at the following:

National Institute for Resources and Environment in Tsukuba where I met with Drs. Takashi Ibusuki and

Koji Takeuchi and their staff who are doing work on carbon dioxide chemistry and global climate change. AIST photocatalysis symposium in Nagoya

Osaka Prefecture University where I met with Professor Masakazu Anpo and his research group that is working on photocatalysts and carbon dioxide chemistry

Osaka University where I met with the research groups of Professors Hiromi Yoneyama and Shozo Yanagida that are doing work on photocatalysis.

During the Japan trip I also went to the research centers for Fuji Electric, Ltd. to meet with Satoshi Nishikata, Senior Research Engineer, and Ishihara Sangyo Kaisha, Ltd. to meet with Hiromi Koga, Deputy General Manager of the Functional Materials Group. Fuji Electric is developing photocatalytic systems and ISK is producing titanium dioxide for photocatalyst applications.

In March of 2000 Representatives of NIRE, AIST, Fuji Electric, and Ishihara Sangyo visited NREL to discuss the work on photocatalytic chemistry.

Presentations on photocatalytic chemistry work at NREL were given at the following conferences:

Federation of Analytical Chemistry \& Spectroscopy Societies, FACCS 98, Austin, TX (October 12, 1998) Petroleum Environmental Research forum, Littleton, CO (January 28, 1998)

$27^{\text {th }}$ Annual Meeting of American Society for Photobiology, Washington, DC, July 10-15, 1999.

$99^{\text {th }}$ General Meeting of the American Society of Microbiology, June 1, 1999, Chicago, IL.

Western States Catalyst Club Symposium, Golden, CO, January, 2000.

ASM National Meeting, June, 2000, Anaheim, CA.

Fifth International Conference on $\mathrm{TiO}_{2}$ Photocatalytic Purification and treatment of Water and Air, June 26-30, 2000, London, Ontario.

International Photoconversion Symposium, Snowmass, CO, July 30 to August 3, 2000.

University of Texas at Arlington, Department of Chemistry, Seminar, February 23, 2001.

The PI served on the DOE panel addressing the "Adequacy Analysis of the Environmental Quality Research \& Development Portfolio" that met in Las Vegas, NV, in May, 2000. 


\section{Transitions:}

The technology in this project has potential application where supercritical or liquid carbon dioxide is used in cleaning or extraction processes that have a high premium on cleaning parts or materials and will recycle the carbon dioxide. The research has proved technical feasibility but there will be many R\&D steps required for the technology to be implemented in an application.

\section{Patents:}

A record of invention has been prepared to cover the applications of photocatalytic oxidation to purification of carbon dioxide in the supercritical, liquid, or gas phases for applications in which carbon dioxide is to be recycled in contaminant sensitive processes.

\section{Future Work:}

The techniques developed in this project can be applied to $\mathrm{CO}_{2}$ conversion chemistry that is required for mitigation of $\mathrm{CO}_{2}$ impact on global climate change, the use of $\mathrm{CO}_{2}$ as a feedstock for chemical and fuel production, and on the use of supercritical or liquid $\mathrm{CO}_{2}$ as a solvent.

\section{Feedback:}

\section{Appendices:}

\section{Quantities/Packaging:}

\section{Literature cited:}

${ }^{1}$ Phelps, M. R., M. O. Hogan, L. J. Snowden-Swan (and others). "Waste reduction using carbon dioxide: A solvent substitute for precision cleaning applicatons," Pacific Northwest Laboratory, Richland, WA, May 1995, 19 pp. (NTIS order no. DE95014629).

${ }^{2}$ McHardy, J., T. B. Stanford, L. R. Benjamin, T. E. Whiting, and T. E. Chao. "Progress in Supercritical $\mathrm{CO}_{2}$ Cleaning," SAMPE Journal, 295, 22-27 (1993).

${ }^{3}$ Montero, G. A., T. D. Giorgio, and K. B. Schnelle, Jr. "Scale-up and economic analysis for the design of supercritical fluid extraction equipment for remediation of soil," Environ. Prog, 15, pp. 112-21 (1996).

4 Tumas, W., D. Morgenstern, S. Feng (and others). "Chemistry and catalysis in supercritical media," Los Alamos National Laboratory, Los Alamos, NM, 1997, 15 pp. (NTIS order no. DE97007835).

${ }^{5}$ Sahle-Demessie, E. S., M. A. Gonzalez, J. Enriquez, and Q. Zhao. "Selective oxidation in supercritical carbon dioxide using clean oxidants," Ind. Eng. Chem. Res., vol. 39, pp. 4858-64 (2000).

${ }^{6}$ P. Srinivas and M. Mukhopadhyay. "Oxidation of cyclohexane in supercritical carbon dioxide medium," Ind. and Eng. Chem. Res., 3312, pp. 3118-24 (1994).

${ }^{7}$ Zhou, L., C. Erkey, and A. Akgerman. "Catalytic oxidation of toluene and tetralin in supercritical carbon dioxide," AICHE Journal, 419, pp. 2122-30 (1995).

${ }^{8}$ Oakes, R. S., A. A. Clifford, K. D. Bartle, M. T. Pett, and C. M. Rayner. "Sulfur oxidation in supercritical carbon dioxide: dramatic pressure dependent enhancement of diastereoselectivity for sulfoxidation of cysteine derivitives," Chem. Comm., 1999, pp. 247-8.

${ }^{9}$ Blake, Daniel M. "Bibliography of Work on the Photocatalytic Removal of Hazardous Compounds From Water and Air Update Number 3 to January, 1999."162 pp.Golden, CO: National Renewable Energy Laboratory, 1999. 
${ }^{10}$ Fox, M. A. and M. T. Dulay. "Heterogeneous Photocatalysis,” Chem. Rev., 93, 341-57 (1993).

${ }^{11}$ Jacoby, William A., Daniel M. Blake, John A. Fennell, James E. Boulter, LeAnn M. Vargo, Marya C. George, and Suzanne K. Dolberg. "Heterogeneous Photocatalysis for Control of Volatile Organic Compounds in Indoor Air." J. Air Waste Manage. Assoc., 46, no. 9 (1996): 891-8.

${ }^{12}$ Wolfrum, Edward, Jie Huang, Daniel M. Blake, Zheng Huang, Pin-Ching Maness, and William A. Jacoby. "Total Oxidation of Bacteria, Bacterial and Fungal Spores, and Biofilm Model Compounds." In Preparation (2000). 